\title{
DESDE EL LIBER (LIBRO) A LA COMPUTADORA
}

\begin{abstract}
Manuel Antonio Quirós Rodríguez
RESUMEN

Este artículo se concentra en los materiales y los instrumentos de escritura en la historia de la civilización occidental desde los tiempos antiguos hasta las computadoras modernas. Estos recursos presentan un continuum esencial para el trabajo filológico en el curso de la historia. El autor utiliza explicaciones etimológicas tanto del latín como del griego, para lograr una mejor comprensión de los distintos vocablos españoles que se consideran.
\end{abstract}

\begin{abstract}
This paper focuses on writing materials and instruments in the history of Western Civilization since ancient times to modern computers. The writing means set a continumm historicum up being essential for the philology work in the course of the history. The author makes use of both Greek and Latin etymology explanations for a better understanding of the different Spanish words which are taken in consideration.
\end{abstract}

\section{Introducción}

Si la filología es una disciplina académica que se ocupa de la letra, la palabra, el texto, y en general, de todo lo relacionado con la ecdótica, la gramática, la lingüística y la literatura, entonces, también ayudada de otras materias, se ocupa de los materiales e instrumentos de escritura.

\section{La Adivinanza de Verona y el acto de escribir}

$1 \uparrow$ separebabouesalbaprataliaaraba \& albaversorioteneba \& negrosemen

$2 \quad$ seminaba

$3 \uparrow$ gratiastibiagimusomnipotenssempiternedeus.

Prescindiendo de la fórmula litúrgica, colocada luego del no. 3, que claramente se nota ser latín, transcribo, de mejor manera, el texto de los números 1 y 2 anteriores:

\author{
Se pareba boues, \\ alba pratalia araba et \\ alba uersorio teneba et \\ negro semen \\ seminaba.
}


¡Adivínese lo que es este pequeño texto! ¡Pues es uno de los documentos más antiguos en lengua italiana! ¡Es una adivinanza! El Indovinello veronese, la Adivinanza de Verona.

¿De qué trata? ¡Hagamos sólo la traducción en castellano y prescindamos de los problemas filológicos de interpretación!:

\author{
Parecían bueyes, \\ blancos campos araba y \\ tenía un blanco arado y \\ sembraba un negra \\ simiente.
}

La adivinanza fue hallada en un libro de oraciones en mozárabe, que se conserva en la Biblioteca Capitolare di Verona (códice LXXXIX, folio 3 r) del siglo VIII o IX. La Edad Media era muy dada al lenguaje simbólico y a las alegorías, y esta adivinanza constituye una metáfora: el acto de escribir: los bueyes son los dedos escribiendo; los blancos campos, el papel; el blanco arado, la pluma con su mango, y la negra simiente, la tinta.

Así, en la Edad Media, mediante una adivinanza se plasma un hecho cultural cuya historia se había iniciado muchos, muchos años antes de Jesucristo.

¡Sí! El alfabeto, la escritura y sus instrumentos y medios tienen su historia, historia, cuyo punto culminante, por el momento, son las modernas computadoras. ¡El homo sapiens siempre creando!...

En este artículo, ayudado por la etimología, pondré en orden y explicaré, sucintamente, un conjunto de materiales y medios de escritura dispersados por doquier, para darles unidad. A no dudarlo, la explicación etimológica proyecta mucha luz sobre la historia de la palabra, y, por ende, del pensamiento, la cultura, la civilización y la historia de la humanidad misma.

A pesar del cambio en los instrumentos y medios para escribir, el alfabeto latino-romano, el papel y la tinta todavía siguen campantes.

¡Con el trabajo en las modernas computadoras cómo nos envidiarían los clásicos griegos y romanos, los monjes de la Edad Media y hasta el mismo Gutenberg!

Las siguientes son las palabras que constituyen el meollo del presente análisis sobre algunos instrumentos y medios de escritura. Casi todas son latinas, alguna que otra de origen latino y unas pocas griegas. Pero todas han sido heredadas por las lenguas romances modernas, ya sea como cultismos o si no como latinismos, en alguno que otro caso, también como voz popular:

Littera $>$ letra, verbum $\mid \pi \alpha \rho \alpha \beta o \lambda \eta>$ palabra, textus, liber $>$ librarius, scriptorium, papyrus $>$ papel, pagina, volumen, explicit $>$ explicare $><$ incipit, titulus; tabulae I tabellae, stylus; caudex I codex, codex rescriptus, pergamena (charta), manuscriptum, editio critica, collatio, constitutio textus, fides, editio(nes) princep(e)s, actus scribendi, minuscula carolina, (aqua) tincta, quaternio(nes) calamus, pluma, lapis.

littera > letra En un alfabeto, letra es el signo gráfico (grafema) como elemento esencial del acto de la escritura, así como el fonema lo es de la expresión oral. El término letra deriva del latín littera, una traducción del griego gramma. Etimológicamente, existe relación entre las palabras literatura y gramática: la primera procede de littera, la segunda, de la voz griega $\gamma \rho \alpha \varkappa \mu \alpha$. De hecho, en la Grecia y Roma clásicas el filólogo era denominado $\gamma \rho \alpha \mu \mu \alpha \tau \iota \kappa o ́ s$ 


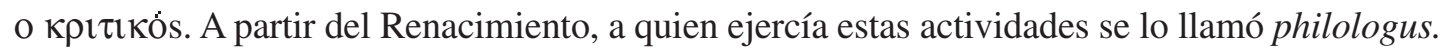
Un conjunto de letras forman un

verbum Palabra $\neq$ res, cosa. En la terminología gramatical, verbum se espacializa en la categoría gramatical homónima para indicar la acción. Verbum $\neq$ vocabulum, el nombre, según lo que mảnifiesta Aristóteles: “...Aristoteles (Rhet.3,2): Orationis duas partes esse dicit: vocabula et verba (= ovó $\mu \alpha \tau \alpha \kappa \alpha \iota$ $\oint \eta \mu \alpha \tau \alpha)$, ut homo et equus, et legit et currit". "Dans la langue de

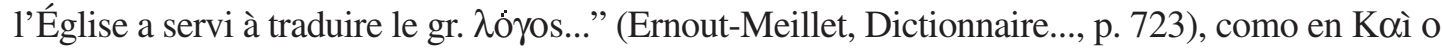

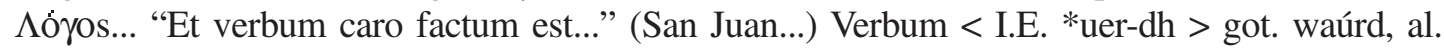
Wort, ingl. word, palabra). Una variante es *wre-tor- $>$ gr. $\rho \hat{\eta} \tau \omega \rho$, orador. Lexema base, wer-, hablar.

Gorgias compara la palabra con la medicina: es un poderoso gobernante que con un cuerpecito pequeño, incluso invisible, produce las obras más divinas; así como, entre las medicinas, una mata y la otra cura, así una razón entristece el alma, mientras que otra la consuela; una tercera asusta; una cuarta le da valor, mientras otras, simplemente convencen. ¡Y esto es, sin más, el fin de la retórica! En otra parte, Gorgias pondera sus efectos tomando como punto de partida la tragedia. Platón expone el papel de la poesía, como lo presenta Edgar De Bruyne en: Historia de la estética. I. Antigüedad griega y romana:

Contemplemos en primer lugar al oyente. Cuando oye cantar a los poetas y oradores el elogio de su ciudad, quédase inmóvil con el alma hechizada. De repente tiene la impresión de haberse hecho más grande, más elevado, más bello. El sentimiento de majestuosidad perdura en él durante tres días y apenas se acuerda de su propia limitación y el lugar en que vive; es como si estuviese ya en la isla de los bienaventurados La palabra es capaz de aplacar el miedo, de disolver la tristeza, de exaltar la alegría, de animar la compasión.

palabra Vimos como el término verbum gramaticalmente se especializó para manifestar una acción y no un estado, cuyo papel le corresponde al sustantivo. Por este motivo, las lenguas romances tuvieron que recurrir a un término nuevo a partir del griego cristiano, a su vez, calco de una palabra hebrea: $\pi \alpha \rho \alpha \beta \circ \lambda \eta \dot{~>~ p a r a ́ b o l a ~>~ p a l a b r a, ~ c o n ~ u n a ~ a m p l i a c i o ́ n ~ d e ~ s i g n i f i c a-~}$ do.

Un conjunto de verba, palabras, constituyen una oración; la unión de varias oraciones, un parágrafo; varios de éstos, un

textus Tela, tejido, contextura, trama, encadenamiento de las palabras de un escrito en una obra impresa de cada quien, o mediante medios mecánicos: el texto (1335). "El texto es un discurso escrito e conformado por varios parágrafos, que, a su vez, está constituido por oraciones" (Fernando Lázaro; Vicente Tusón. Curso...p. 304). Y así, un libro generalmente está conformado por un texto grande o por textos de dimensión menor, los cuales impregnan sus páginas, para cuya elaboración, han existido, en el transcurso de la historia de la escritura, varios medios de trazar las litterae, letras. El verbo relacionado con textus es texo,-is, texui, textum, texere, tejer, entrelazar, cuyo lexema es teks-, tejer, fabricar, al cual pertenece también la palabra griega $\tau \varepsilon \chi \nu \eta ்$, arte, habilidad, destreza.

manuscriptum Manuscrito. Palabra que comienza a ser aplicada desde el siglo II para designar el carácter auténtico (el autógrafo) de un documento sin relación alguna con la escritura a mano. La palabra procede de manum scribere.

editio critica Edición crítica No basta con poseer los textos antiguos, cuya transmi- 
sión verídica es una labor penosa, nada fácil, que, por eso, está sometida a todo un proceso filológico suministrado por la ecdótica con el fin de obtener la reconstrucción de un texto original genuino y verídico mediante la

collatio Lectura cuidadosa de los testimonios manuscritos mediante la comparación de distintas variantes o lecturas de un texto (tradición textual) para analizar las relaciones existentes entre los manuscritos hasta dar con un posible original, original que puede presentarse de la siguiente manera:

En un rollo de papiro escrito en columnas.

En un pergamino en forma de quaternio.

En un papel provisto de una filigrana o marca de agua, la cual ayuda en mucho para la datación.

En un texto salido de la imprenta (incunable), en donde se obtiene la editio princeps, durante el Renacimiento.

En una edición actual.

La palabra collatio también significa conferir un grado académico. Desde el punto de vista de la gramática, tal palabra procede del supino del verbo confero, contuli, conlatum, conferre, cotejar, comparar, conferir.

constitutio textus Constitución del texto. Procedimiento que es fruto de la corrección de los errores que hayan sobrevenido en un texto en el transcurso de su existencia, y a su reconstrucción lo más fidedigna posible al original mediante la crítica textual.

Para todos los procedimientos anteriores se necesita la

fides Autenticidad, verdad. Fe y confianza son las virtudes que todo lector ha de poseer ante el trabajo de las ediciones críticas de los autores antiguos efectuada por los filólogos, pues de tales autores no se poseen los originales escritos por su propio puño y letra.

Naturalmente, no siempre se ha contado con los bellos libros actuales, ni con máquinas de escribir manuales o eléctricas, ni mucho menos con las modernas computadoras; por eso han sido diversos los medios para plasmar lo escrito, de modo que perdure en el transcurso de la historia.

En el caso de textos del Renacimiento, se tiene la

editio princeps (editiones principes) Las primeras ediciones de los autores clásicos salidas de la imprenta en los inicios de ésta durante el Renacimiento, y que no siempre son confiables.

Con un texto o varios de regular tamaño se puede constituir un

liber Libro, en griego, $\beta i \beta \lambda o s$ (Biß $\beta$ os era también un puerto fenicio, situado en Siria, Asia Menor). Liber significa, primero, corteza (de un árbol), más bien, la parte viva, en forma de capa fina y delgada (película) o laminillas fibrosas situadas entre la madera y la corteza, de donde, precisamente, tomó, después, su nombre el libro. Como material de escritura, el liber fue empleado antes del papiro egipcio. De librum viene:

librarius Librero romano, o el copista de libros. Los primeros libros fueron elaborados en Roma, aunque eran más antiguos que los papiros, como manifesté. Algunos libreros romanos hacían que se efectuaran copias de libros de mucho uso, para lo cual contaban con una gran cantidad de escribientes al dictado; algunos de éstos eran esclavos, quienes les copiaban obras de una gran valor a sus muy ricos amos bibliófilos, para coleccionarlos o para intercam- 
biarse con amigos y conocidos.

Tito Pomponio les enseñó a ciertos esclavos griegos instruidos a hacerse copistas (servi litterati o librarii) para cuyo fin, uno de ellos les leía a los otros lo que debían transcribir; de este modo se obtenían, simultáneamente, varias copias. Muchos libros (manuscritos) llegaban a Roma como botín de guerra; primeramente, fueron los generales y la gente rica quienes coleccionaban libros, luego, la gente instruida como Cicerón. Tiranión llegó a poser unos 30.000 volúmenes.

La primera biblioteca pública fue abierta por Asinio Polión en el 30 a. C., aunque ya Julio César había concebido la idea. Los emperadores Augusto, Vespasiano y Adriano fundaron y abrieron bibliotecas. En 476, cuando cayó Roma en poder de los bárbaros, la Urbe tenía ya 28 bibliotecas. Las tabernae eran tiendas romanas, en donde, además de tertulias, se efectuaban lecturas públicas.

En la Edad Media, siguiendo la tradición romana, un monje les dictaba a otros siete monjes, en el scriptorium, pl. scriptoria: sitio de una biblioteca en donde, sobre todo, a partir del siglo X, se solían copiar, decorar y encuadernar manuscritos, generalmente, textos clásicos, bíblicos y patrísticos de cuyo contenido se nutrieron las personas cultas de la Edad Media. El scriptorium contaba con una sala, el calefactorium, único lugar provisto de calefacción, o de varias celdas pequeñas con distintos usos. El monje copista contaba con un pupitre con su silla, el cual tenía dos superficies que permitían el trabajo simultáneo de dos monjes. Monjes novicios eran también empleados en trabajos de mejor calidad como el trazo de renglones verticales para el acomodamiento de las respectivas letras. Generalmente, los dignatarios civiles y eclesiásticos encargaban copias, muchas veces, a los mejores calígrafos, si el trabajo debía ser delicado. La decoración y la iluminación corrían a cargo de monjes especialistas. Antes de que apareciera la minúscula carolina, los monjes usaron el tipo de letra empleada por los romanos: la cursiva mayúscula o uncial, la semiuncial y la capital o mayúscula cuadrada y, a veces, la rústica. La labor monacal de escritura de textos se extendió hasta finales del siglo XI, cuando fueron sustituidos por laicos, quienes se organizaron en gremios y entonces aparecieron libros con otra temática, no sólo la religiosa, sobre todo, cuando tales gremios, a veces aunados en cofradías, comenzaron a pulular cerca de las nacientes universidades, con cuya creación aparecieron los stationarii, libreros medievales.

Ernst Robert Curtius, Literatura europea... I (págs. 423-479), presenta algunas metáforas relacionadas con el libro como símbolo en Grecia, Roma, la Biblia, la Temprana Edad Media, la Alta Edad Media, el Libro de la Naturaleza...

Uno de los primeros medios para la escritura informal fueron las

tabulae I tabellae (ceratae) Tablillas, registros, libros de cuentas. Las tablillas, elaboradas de madera, o de marfil y recubiertas de cera (por eso se las llamaba también cerae), eran un medio cotidiano de escritura informal y pasajera para toda clase de apuntes y notas. Se dividían en díptica, tríptica y políptica, según el número de ellas: una, dos, varias...Hubo tablillas que se usaron como libros de bolsillo y entonces se las llamaban pugillatores. En Roma, las tabulae publicae eran los archivos nacionales.

Luego del liber aparece el

papyrus $<\pi \alpha \pi v \rho o s$. El papiro es una planta acuática que crece en las 1 orillas del río Nilo (papyriferi septemflua flumina Nili) de las Ciperáceas (cyperus papyrus), a modo de caña alta (de hasta $3.50 \mathrm{~m}$.) y culmina con un penacho de flores. Por eso fue empleado de primero 
en Egipto, hace unos 5000 años. El papiro, como material de escritura en la Antigüedad, constituyó un gran adelanto durante unos 4000 años. Sin él no se puede concebir el origen de la filología en Alejandría. De Egipto pasó a Grecia y a Roma: los papiros encontrados en Egipto contienen una gran variedad temática en idioma griego, inclusive, de la vida diaria de la gente del pueblo, y no sólo textos sagrados; la literatura romana circuló en tal forma, aunque los rollos eran más bien empleados en notas y en documentos oficiales. En algunos sitios de Europa, se usó hasta el siglo XI.

Plinio el Viejo (Naturalis historia XIII, 68 sigs.) informa sobre la manera de ser extraído y elaborarlo: la parte interna del tallo, con una contextura esponjosa y de color blanco, era cortada en tiras sutiles y delgadas, las cuales se sobreponían unas a otras en sentido inverso. Una vez obtenido tal material, o era machacado con un martillo, o si no, raspado hasta obtener finas láminas: las hojas o páginas que se pegaban unas a otras para formar una larga banda.

En griego, la palabra papiro es extranjera y de origen desconocido. En latín, está atestiguada desde el poeta Catulo.

Pero los egipcios, a pesar de haber sido un pueblo con un alto grado de escritura, no pasan por ser los inventores del alfabeto, cuyo mérito es, más bien, de los fenicios.

Palabras integrantes del papiro son:

\section{página, volumen, explicare (explicit vs. incipit).}

página < pango, pepigi (pegi), panxi, pactum, pangere, pegar, clavar, fijar, determinar, componer obras literarias, escribir, cantar, establecer sólidamente, concluir, pactar, de donde pacto < pactum, paz < pacem, país < pagensem. El lexema ie. es pak-, atar, fijar. Pagina es la parte interna u hoja del papiro cortada en forma de bandas (tomos) dentro del mismo tallo y fijada o pegada lateralmente a otra(s) de modo a constituir una serie (de páginas) sobre las cuales se escribía en una sola columna, de donde, página de un libro, de una revista, de un periódico, de un cuaderno, y hasta de una computadora.

La página, por ser susceptible de ser arrollada-desenrrollada constituía el

volumen Rollo, tomo, volumen < volvere, arrollar, enrollar, pues un manuscrito se arrollaba, o desenrollaba alrededor de un eje o cilindro, $\kappa v \lambda \iota v \delta \rho o s$. El volumen tenía unos 13 m. a 30 de largo por 25 de ancho. El volumen o rollo de papiro consistía en una serie de folios extraídos de él y pegados lateralmente unos a otros. Así pues, el papiro estaba conformado por el volumen.

evolvere o explicare Desenrollar el volumen, de donde explicar.

explicit < volumen explicitum est El rollo (de papiro) fue desdoblado, desplegado o desenrollado; de aquí procede la connotación de haber sido ya explicado (el libro ya terminó, pues ya fue explicado o desenrollado.) El verbo latino es plicare, plegar: ex + plicare, desplegar, en contraposición al hic incipit, aquí comienza la materia del libro...

Posterior al liber, a las tabulae y al papyrus se encuentra el

caudex I codex, tronco, corteza del árbol; códice y código. La palabra es indoeuropea, en dondel a raíz kau- significa cortar, golpear.

El codex como material de escritura es producto del pergamino, en forma de quaternio, cuaderno,y fue elaborado a semejanza de las tablillas enceradas griegas y romanas, por lo cual adquirió la forma de libro. Cuando se comenzó a emplear el pergamino como material de 
escritura, al libro, producto de la respectiva elaboración, se le dio el nombre de códice.

La palabra pergaminus es un derivado de Pérgamo, ciudad del Asia Menor (en su origen, una pequeña colonia conformada por una mezcla de pueblos, situada en una colina fortificada en la Mesia) en donde se inventó el pergamino cuya materia prima era una piel de cordero, ternera, cabra, cordero, antílope, o avestruz, la cual, una vez limpiada del pelo y de pellejillos, macerada o raída con piedra pómez, adobada y raspada, era sometida a tensión, secada y pulida con cal o un acabado de tiza para ser usada como material de escritura por ambas caras, desde el siglo I d. C. Un tipo de pergamino más acabado y fino era la vitela, elaborado a base de piel de oveja, cabrito o antílope sobre los cuales se aplicaba una pluma metálica. El pergamino fue también usado por los romanos.

Anteriormente a Constantino el Grande, el libro-códice era de mayor uso en la parte griega del Imperio, pues poseía una mejor tradición cultural cristiana; en la parte occidental, más bien se escribía en latín, pero dada la escasez del material de escritura, la tradición evangélica era oral; luego del Edicto de Milán del 313, muchos prelados y monasterios fueron aumentando sus bibliotecas privadas y el libro cristiano adquirió mayor categoría que el pagano.

No se sabe, bien podría ser una leyenda, que los Ptolomeos, por celos intelectuales, no continuaron facilitándoles a los de Pérgamo más papiro para que copiaran libros en la biblioteca de los Atálidas, recientemente fundada. En todo caso, comienza a existir, ocasionalmente, desde el siglo II. a. C., y, continuamente, desde el siglo IV. d. C.

El pergamino de piel de cordero o de ternera permitía que se escribiera por ambos lados, y el de vitela era el de superior calidad, pues no absorbía la tinta ni la pintura, por lo que era eso era preferido para el trabajo de iluminación.

El pergamino era también más consistente, y por consiguiente, más duradero que el papiro; por este motivo y por su mayor facilidad de manejo y de transporte, fue preferido desde los primeros siglos del cristianismo en la configuración de quaterniones y de quiniones (quaternio > cuaderno < quattuor, cuatro), debido a sus folios con cuatro caras o pliegos: dos del reverso y dos del anverso.

El codex es al pergamino lo que el volumen al papiro, y el primero es el sucesor del segundo. En derecho, la palabra codex se especializó e indicó una colección sistemática de normas jurídicas o leyes; y en farmacia, el repertorio oficial de drogas y preparados de cada país. En contraposición al volumen (de papiro), el codex tiene forma de libro y sobre él se solía escribir con pluma de oca. Como lo expresé, para escribir, los primeros cristianos preferían el códice, en contraposición a los judíos que lo hacían sobre rollos, pues las ventajas del códice sobre el papiro eran las siguientes:

Posibilidad de escribir por ambas caras.

Capacidad de ser apoyado en una mesa o de ser sostenido con una mano.

Mejor facilidad de ser transportado, principalmente, para los viajes de apostolado.

Mayor durabilidad, dada la resistencia del material: cuero.

Mejor facilidad para ser escondido, sobre todo, durante las persecuciones contra los cristianos.

Mejor localización de un pasaje para leerlo durante las reuniones de los primeros cristianos. 
Con el inicio de las invasiones de los germanos, peor dificultad de adquirir el papiro egipcio.

pergamena charta Papel de pergamino. En griego, charta $<\chi \alpha \dot{\rho} \rho \tau$ s, papel.

codex rescriptus Códice vuelto a escribir Un sinónimo es la palabra griega palimsesto. Es común que textos de la antigüedad pagana hayan sido borrados para escribir, en su lugar, textos cristianos. Palimsestos son el De re publica, de Cicerón, el Codex Ambrosianus con comedias de Plauto, y partes de un palimsesto con obras de Eurípides que fue encontrado en Jerusalén. Un caso típico de palimsesto, de gran importancia para el estudio de latín vulgar, es el Appendix Probi, reescrito por monjes de Bobbio, norte de Italia, sobre parte de una gramática del Pseudoprobo.

Existe una relación semántica estrecha entre la palabra codex o caudex y la palabra latina liber.

papel Las dificultades en adquirir el papiro, su misma fragilidad, su incapacidad para soportar la humedad, además de lo difícil y caro de obtener pieles para los pergaminos, indujeron a la introducción del papel, que ya había sido producido por los chinos desde el 100 d. C., mediante la unión de fibras.

La palabra se deriva de papiro, aunque nada tenga que ver con éste en cuanto al material. La evolución lingüística de la palabra papiro hacia la palabra papel es como sigue:

$\pi \alpha \pi \cup ́ \rho o s ~>~ l a t$. papyrus $>$ *paperus $>$ papilus $>$ papel.

El papel fue inventado en China, cuyo secreto para elaborarlo fue develado por los árabes, 751, en Samarkanda. Luego, los mismos árabes produjeron papel en Oriente. En el Sur de España, el papel existe desde el siglo XII. Los molinos para fabricar el papel comenzaron a usarse en el occidente desde el siglo XII a partir del lino como materia prima y luego a partir de la pulpa de madera. Las láminas medían de 15 a $45 \mathrm{~cm}$.

El lugar y la fecha de invención, producción, comercio e itinerario del papel, a partir del barnbú, la seda y el trapo de hilo, y no del papiro, son los siguientes:

Lugar y fecha de inicio: China: Tsai Lun (105 d. C.) $\rightarrow$ Tung Huang ( 150 d. C.) $Æ$

1. Lou Lang (200d.C.); Niya (250-300 d.C.; $\rightarrow$ Turquestán chino: Turfan (399 d.C. $\rightarrow$ Tur

questán ruso: árabes $\rightarrow$ Samarcanda (751) $\rightarrow$ Bagdad y Damasco (793) $\rightarrow$ Egipto: Cairo 900

$\rightarrow$ Fez (1100) $\rightarrow$ Península Ibérica x árabes: Játiva (1150) $\rightarrow$ Francia: Herault (1189) $\rightarrow$ Alemania: Nuremberg (1319) $\rightarrow$ Colonia (1320) $\rightarrow$ Italia: Treviso (1340) $\rightarrow$ Londres (1494) $\rightarrow$ Países Bajos: Dordrech) (1486) $\rightarrow$ América: Filadelfia (1690).

titulus Título, rótulo, inscripción. Trozo de pergamino unido al rollo en donde se indican los datos esenciales para conocer tal pergamino: autor, título... Hasta el siglo V, el título de un libro se encontraba al final de la obra. Un sinónimo es index.

\section{Instrumentos para trazar la escritura}


Los materiales anteriores servían para escribir y los siguientes constituyen medios para trazar la escritura, por ejemplo:

\section{tinta, stylus, calamus pluma, lapis.}

aqua tincta Tinta. A partir de carbón vegetal, al que se le agregaba agua y goma, se obtenía una tinta de negro intenso y brillante para ser empleado en las escritura de papiros. En tinta roja iban los títulos y los epígrafes. El verbo es tingo, tinxi, tinctum, tingere, mojar, impregnar, empapar (en gr. $\tau \dot{\varepsilon} \gamma \gamma \omega$, mojar.) Se dice, en latín: tunica sanguine tincta, túnica empapada en sangre; homo tinctus litteris, hombre empapado de cultura.

stylus, Estilete, estilo Sobre las establillas se escribía con el estilete o estilo. La palabra precedente, de origen griego, significa серо, en terminología bélica; tallo, en terminología botánica; cualquier tallo, vara, punta, en sentido general. Luego, en un sentido especializado, punzón o estilete hecho de hueso, madera, bronce, hierro, plata, marfil para cavar (escribir) en

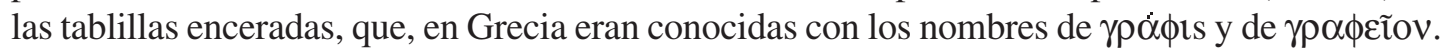

El stylus era el instrumento de escritura empleado por los romanos cuando trazaban sus letras sobre tablas de madera de un color claro, recubiertas por una capa fina de cera negra. Los trazos aparecían como caracteres blancos sobre un fondo oscuro. En la parte superior, era redondo para borrar y alisar nuevamente la cera que cubría la tablilla. Para escribir nuevamente, tales trazos eran borrados ablandando la cera en contacto con el calor o nivelando la superficie.

Por vía metonímica, en literatura, el estilo es la manera propia y diferencial de cómo se expresa cada persona por escrito de acuerdo con cánones gramaticales como medio para la elocución: ornato de las palabras mediante la expresión figurada, lo cual es una característica del lenguaje literario.

La mejor afirmación sobre el estilo literario es la externada por Georges Louis Leclerc, conde de Buffon, nacido en Borgoña en 1707 y muerto en París en 1788. En 1752, este científico fue nombrado miembro de la Academia Francesa y, el 25 de agosto de 1753, en su discurso de bienvenida, externó Le style c'est l'homme, (El estilo es el hombre mismo), dentro del siguiente contexto:

Sólo las obras bien escritas han de pasar a la posteridad. La abundancia de conocimientos, la novedad de los descubrimientos no son garantía de inmortalidad. Si las obras que las condensan están escritas sin gusto, sin nobleza, sin genio, perecerán; porque los conocimientos, los sucesos, los descubrimientos, se subliman cuando pasan por manos hábiles. Por otra parte, son exteriores al hombre; en cambio el estilo es el hombre mismo.

Aunque un escritor latino se le había adelantado al conde de Buffon, cuando escribió stylus virum arguit, el estilo es una prueba del hombre.

Para Romain Rolland, Oratio vultus animi est, el estilo es la cara del alma, pues el estilo es el sello personal inherente a cada autor.

También, en modo objetivo, dejando lo personal, es la característica inherente al habla general o a un determinado género artístico: estilo clásico, estilo románico, estilo gótico, estilo epistolar, estilo periodístico; incluso, una manera de expresar ciertas oraciones: estilo directo vs. estilo indirecto; estilo nominal en contraposición al estilo verbal 
El estilo también se puede manifestar mediante arcaísmos y neologismos (aspectos temporales) provincialismos (aspectos locales) vulgarismos o elementos de otras lenguas (aspectos sociales), prosaímos y poetismos (aspectos literarios) según Gerhard Jäger, p. Einführung,... págs. 118 a 121.

¡El estilo no es la gramática, pero la presupone! Una persona sin conocimientos gramaticales es como un músico sin conocimiento de las notas ni del solfeo.

En griego y en latín, era la retórica la que se ocupaba del estilo.

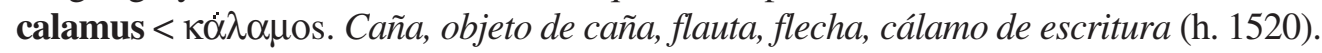

Instrumento elaborado de caña, tallado con punta como material de escritura común a partir del siglo III.

pluma Esta metáfora fue tomada del uso antiguo de usar plumas afiladas de ave, principalmente, de oca, como instrumento para escribir. La palabra es un latinismo.

lapis Lápiz. Cuando se escribe a mano y no se hace uso de la tinta o de algo parecido, como el en caso del bolígrafo, se emplea el lápiz, término latino que, en castellano, procede del italiano lapis, primero de uso pictórico, luego, en la escritura. Consiste en una piedra de donde procede la barrita de grafito.

\section{máquina de escribir, computadora}

Con la máquina de escribir se inicia, en forma manual y personal, el uso del teclado con las letras del alfabeto. Un empleo más rápido se obtiene con las máquinas eléctricas y luego con las electrónicas, las cuales fueron superadas por la computadora, cuyo uso cae en la denominación de

informática I computación Esta rama actual del saber, y más que del saber, excelente herramienta idiomática e intelectual, es el estudio para obtener conocimientos científicos y técnicos con el fin de tratar, en forma casi automática, toda clase de informaciones y de cálculos.

Ambas palabras son de origen latino: la primera posee se deriva de la preposición in y el sustantivo forma; la segunda, de la preposición cum y el verbo putare, cuyo derivado popular es contar. El castellano toma la palabra del idioma francés, informatique.

Para la palabra computadora, algunos idiomas modernos toman esta palabra, otros, como el francés y el italiano la derivan de ordenare: fr ordinateur, it ordinatore (lat. vulg. ordiniare, ordeñar.)

La mayor parte del léxico latino empleado en la informática ha penetrado en los idiomas modernas a través del inglés, en cuyo campo ha creado una configuración léxica internacional; de hecho uno de los primeros creadores del sistema computativo, en 1890, fue Herman Hollerith para elaborar el censo de los Estados Unidos de América.

\section{El alfabeto latino en la computación, el correo electrónico y la internet en un ámbito mundial}

En la Edad Media se desarrolló la más importante manera de trazar la escritura: La minuscula carolina Esta forma de escritura de gran valía para la historia de la cul- 
tura de Occidente, comenzó a ser implantada en 780 por Alcuino de York (735-804), clérigo del Círculo Carolingio en el scriptorium del Monasterio de San Martín de Tours. Consistía en una especie de letra semiuncial regular, redondeada, clara, bella y separada una de otra, de fácil lectura, equivalente, más o menos, al tipo de escritura de caracteres de imprenta empleado hoy. Tal escritura reemplazó, en Europa occidental, a las escrituras nacionales y fue empleada por los impresores del siglo XVI. En España, la carolina sustituyó, en el siglo XI, a la gótica, llamada toledana.

En la actualidad, las computadoras cuentan con hasta más de 100 maneras de trazar las letras del alfabeto en su sistema tipográfico.

El aporte alfabético de las modernas computadoras consiste en la elaboración, a modo de tema con variaciones, de una amplia gama de tipografías con nombres bastantes extraños. La de mayor es el Times New Roman. Solo se da el mando y aparece desplegada, en la pantalla, una amplia gama de alfabetos.

Recalco la imprescindible importancia y necesidad del alfabeto latino-romano para el uso de la computación y para la internet, y, en general, para todo el sistema informático de casi todo el mundo.

Parece algo muy fácil, y lo es, pero ese algo fácil posee una larga, difícil y complicada trayectoria histórica. ¡Hasta dónde ha llegado el ser humano para expresar su pensamiento mediante la escritura, tan esencial como éste, el sol,el agua, el fuego, el aire y la rueda.

¡La invención del alfabeto-escritura dejó atrás la penumbra de la prehistoria para adentrarse en la luz de la historia, en donde Roma, a partir del 21 de abril del 753, hace 2752 años, comenzó a poner más que un grano de arena!...

De nada le serviría a una persona tener la más cara y sofisticada de las computadoras si ella no conoce el alfabeto, y por lo tanto, no sabe leer, escribir y firmar. Por lo tanto, mucho más importante que la computadora es el alfabeto y la escritura, incluso, el conocimiento gramatical ¡La computadora es un medio y no un fin!...Además, para escribir bien, se debe conocer, en forma cabal, el respectivo idioma en su gramática y estilo, pues esto no se obtiene mediante la computadora., sino por el largo proceso del aprendizaje escolar, colegial y universitario Y según mi parecer, es mucho más difícil aprender perfectamente un idioma que aprender el manejo de los distintos lenguajes de computación. Parece que éstos se aprenden en tres meses. ¡Un idioma, durante toda la vida!...

Y también las computadoras siguen, en mucho, la tradición: hacen uso de palabras, verba, parabolae; signos de puntuación, inventados en Alejandría; textos, textus; paginae, tituli; litterae, letras; signa, signos, y principalmente, del alfabeto y de la escritura latino-romanos.

\section{Actus scribendi, el acto de escribir}

Todos los instrumentos y medios precedentemente nombrados tienen la finalidad de estampar por escrito el pensamiento, la imaginación, las emociones humanas, la cultura y la vida social y artística del ser humano mediante el acto de escribir $(1140)<$ scribere, hendir, agrietar, rasgar, aruñar, rasguñar, trazar marcas y símbolos de cuando se comenzaron a trazar letras sobre tablillas enceradas, lo cual consistía en hendir y agrietar la tablilla encerada 
para arrancarle letras, palabras y oraciones por medio del estile. Los siguientes verbos: castellano, escribir; italiano, scrivere; portugués, escrever; rumano, scrie; francés, écrire; alemán, schreiben; inglés, to write, neerlandés, schrijven; sueco, skriva se derivan del latín verbo latino scribere (gr. $\gamma \rho \alpha \phi \varepsilon \imath v)$ uno de los actos esenciales mediante los cuales el homo sapiens se diferencia de las ferae, los animales irracionales. ¡Si no que lo digan los Humanistas del Renacimiento!

Para el establecimiento y restablecimiento de una edición crítica original y verídica, principalmente de un libro antiguo: papiro, códice, incunable, lo que constituye la filología stricto sensu, el idioma oficial ha sido y es el latín. Por eso existe una gran cantidad de terminología especializada en este idioma.

En el presente, con los medios que se tienen a disposición, es muy fácil escribir, siempre y cuando se domine la gramática y el estilo de la respectiva lengua. ¡Pero no siempre fue así!: superando dificultades de todo orden, y siguiendo también una tradición anterior al cristianismo, luego de que los monjes, o un monje, lograba(n) concluir una obra, a veces se redactaban ciertos coloofones a modo de metáforas o de similes. Por ejemplo, el siguiente exalta la excelencia del arte de escribir al compararse el marinero que llega a puerto feliz luego de una larga navegación:

Labor scribenti refectio est legentis;

Hic deficit corpora, ille proficit mente

Qu am suavis est navegantibus portum extremum,

Ita est scriptori novissimus versus.

Ora se ponderan los efectos fisiológicos, negativos sobre su pobre cuerpo, debido al trabajo tan prolongado, el cual

Dorsum inclinat, costas in ventrem mergit

et omne fastidium corporis nutrit,

ora le echa en cara, a quien no sabe escribir de que ni siquiera se dé cuenta de lo difícil de su esfuerzo:

Scribere qui nescit, nullum putat esse laborem,

Tres digiti scribunt, totum corpusque laborat.

O si no, simplemente se limita a consignar una fórmula general, como

Deo gratias;

o,

Finito libro, sit laus et gloria Christo.

\section{Conclusión}




\section{DIRECCIONES DE LOS COLABORADORES}

\section{María Amoretti Hurtado}

Escuela de Filología, Lingüística y

Literatura.

Universidad de Costa Rica.

San Pedro, San José, Costa RicA.

\section{Ruth Cubillo}

Escuela de Filología, Linguiística y

Literatura.

Universidad de Costa Rica.

San Pedro, San José, Costa RicA.

\section{María Esther Conejo}

Escuela de Filología, Lingüística y

Literatura.

Universidad de Costa Rica.

San Pedro, San José, Costa RicA.

\section{Eugenio Murillo}

Facultad de Bellas Artes.

Universidad de Costa Rica.

San Pedro, San José, Costa Rica.

emurillo@cariari.ucr.ac.cr

\section{Gastón Salamanca}

Calle Rumania, No. 3044,

Población "Esfuerzo unido",

Talcahuano, CHILE.

E-MAIL: gsalaman@udec.cl

\section{Helene C. Weldt-Basson}

Fordham University.

3500 Maxwell Ct.

Bloomfield Hills, Michigan 48301.

\section{Gastón Salamanca}

Calle Rumania, No. 3044,

Población "Esfuerzo unido",

Talcahuano, CHILE

E-MAIL: gsalaman@udec.cl

\section{Mario Portilla Chaves}

Escuela de Filología, Lingüística y

Literatura.

Universidad de Costa Rica.

San Pedro, San José, Costa RicA.

\section{Adolfo Constenla Umaña}

Escuela de Filología, Lingüística y

Literatura.

Universidad de Costa Rica.

San Pedro, San José, Costa RicA.

\section{Flor Garita Hernández.}

Escuela de Filología, Lingüística y

Literatura.

Universidad de Costa Rica.

San Pedro, San José, Costa RicA.

\section{Anita Arrieta}

Escuela de Filología, Lingüística y

Literatura.

Universidad de Costa Rica.

San Pedro, San José, Costa RicA.

\section{Kattia Chinchilla}

Escuela de Filología, Lingüística y

Literatura.

Universidad de Costa Rica.

San Pedro, San José, Costa RicA.

José-Miguel Rodríguez

Facultad de Ciencias Sociales.

Universidad de Costa Rica.

San Pedro, San José, Costa RicA.

\section{Sergio Valverde}

Escuela de Estudios Generales.

Universidad de Costa Rica.

San Pedro, San José, Costa RicA. 
Kari Meyers Skredsvig

Escuela de Lenguas Modernas.

Universidad de Costa Rica.

San Pedro, San José, Costa RicA.

\section{Carlos Sánchez Avendaño}

E-MAIL: csanda@racsa.co.cr 